\title{
Ambulatory Blood Pressure Monitoring and Microalbuminuria in Normotensive Subjects with Insulin- Dependent Diabetes Mellitus
}

\author{
Cesar N issan Cohen, Francisco Manes A lbanesi Fo, Maria de Fátima Gonçalves, Marília de Brito Gomes
}

\author{
Rio de Janeiro, RJ - Brazil
}

\begin{abstract}
Objective - To assess the association between microalbuminuria with ambulatory blood pressure monitoring in normotensive individuals with insulin-dependent diabetes mellitus.
\end{abstract}

Methods - Thirty-seven patients underwent determination of the rate of urinary excretion of albumin through radioimmunoassay and ambulatory blood pressure monitoring. Their mean age was $26.5 \pm 6.7$ years, and the mean duration of their disease was 8 (1-34) years. Microalbuminuria was defined as urinary excretion of albumin $\geq 20$ and $<200 \mu \mathrm{g} / \mathrm{min}$ in at least 2 out of 3 urine samples.

Results - Nine $(24.3 \%)$ patients were microalbuminuric. Ambulatory blood pressure monitoring in the microalbuminuric patients had higher mean pressure values, mainly the systolic pressure, during sleep as compared with that in the normoalbuminuric patients (120.1 $\$ 8.3 \mathrm{vs} 110.8 \pm 7.1 \mathrm{~m}$ $m H g ; p=0.007)$. The pressure load was higher in the microalbuminuric individuals, mainly the systolic pressure load during wakefulness [6.3(2.9-45.9) vs 1.6(0-16\%); $p=0.001]$. This was the variable that better correlated with the urinary excretion of albumin $\left(r_{s}=0.61 ; p<0.001\right)$. Systolic pressure load $>50 \%$ and diastolic pressure load $>30 \%$ during sleep was associated with microalbuminuria $(p=0.008)$. The pressure drop during sleep did not differ between the groups.

Conclusion - Microalbuminuric normotensive insulin-dependent diabetic patients show greater mean pressure value and pressure load during ambulatory blood pressure monitoring, and these variables correlate with urinary excretion of albumin.

Key words: ambulatory blood pressure monitoring, insulin-dependent diabetes mellitus, diabetic nephropathy

Hospital Universitário Pedro Ernesto - Universidade do Estado do Rio de Janeiro Mailing address: Cesar Nissan Cohen - Rua Dona Romana, 621 - 20710-200 - Rio de Janeiro, RJ, Brazil

English version by Syela Maris C. Gandour
The association between diabetes mellitus and cardiovascular disease has been reported in the literature. Clinical diabetic nephropathy correlates with greater mortality rate and to the prevalence of coronary artery disease and hypertension ${ }^{1}$. In this context, arterial hypertension assumes great importance because its frequency in diabetes mellitus is two times higher than that in nondiabetic patients, and increases cardiovascular risk ${ }^{2}$.

Approximately $40 \%$ of the patients with insulin-dependent diabetes mellitus develop clinical diabetic nephropathy, which is defined as a urinary excretion rate of albu$\mathrm{min}>300 \mathrm{mg} / 24 \mathrm{~h}^{3}$. Clinical diabetic nephropathy is recognized as an important cause of cardiovascular morbidity and mortality in this population ${ }^{1}$.

Microalbuminuria, defined as a urinary excretion rate of albumin between 20 and $200 \mu \mathrm{g} / \mathrm{min}$ in at least 2 out of 3 nocturnal urine samples ${ }^{4}$, in addition to being related to the development of clinical diabetic nephropathy also has a prognostic significance from the cardiovascular point of view. The association of microalbuminuria with dyslipidemia and changes in coagulation, which are known factors involved in atherosclerosis, has been described as has its association with pressure elevation, even when within the normal limits ${ }^{3,5,6}$.

Because of the importance of the detection of microalbuminuria in the insulin-dependent diabetic patient and its association with the casual elevation of blood pressure, recent studies ${ }^{7-9}$ have shown, with the use of ambulatory blood pressure monitoring, higher pressure levels and higher pressure load in subgroups of microalbuminuric diabetic patients as compared with normoalbuminuric diabetic patients. This confirms the importance of the ambulatory blood pressure monitoring in assessing patients with incipient diabetic nephropathy.

This study aimed to assess the mean pressure values, the pressure load, and the circadian rhythm of blood pressure during its ambulatory monitoring in normotensive insulin-dependent diabetic patients, dividing them according to the presence of microalbuminuria. 


\section{Methods}

Thirty-seven patients were chosen from 52 insulin-dependent diabetic patients who were previously and regularly followed up in the diabetes sector of the Hospital Pedro Ernesto of the UERJ. The mean age of the 37 patients was $26.49 \pm 6.75$ years, $59.5 \%$ of them were females, and the mean duration of their diabetes was 8 (1-34) years. These 37 patients underwent determination of the urinary excretion rate of albumin and ambulatory blood pressure monitoring. The inclusion criteria were as follows: maximum age of 40 years; casual blood pressure $<140 / 90 \mathrm{mmHg}{ }^{10}$; absence of cardiac or thyroid disease and of clinical nephropathy (urinary excretion rate of albumin $>200 \mu \mathrm{g} / \mathrm{min}$ ). The patients studied had been insulin-dependent since the diagnosis, they had no symptoms of decompensation of the diabetes, and were not using any cardiovascular medication. The patients with systemic infection and other renal diseases evidenced by hematuria and abnormal urinary sediment were excluded from the study.

The patients were instructed to collect 3 samples of nocturnal urine during a period of 6 months avoiding strenuous physical activity on the day of sample collection. The urinary volume was recorded and the aliquots stored in vials at a temperature of $-20^{\circ}$ for further analysis. The albumin concentration was determined through radioimmunoassay with double antibodies (Diagnostic Products Corporation, Los Angeles, CA) ${ }^{11}$, and the urinary excretion rate of albumin was defined by the mean of the 3 samples. A urinary excretion rate of albumin $\geq 20 \mu \mathrm{g} / \mathrm{min}$ and $<200 \mu \mathrm{g} / \mathrm{min}$ in at least 2 out of 3 urine samples was considered microalbuminuria ${ }^{4}$. The sensitivity of the method was $0.30 \mu \mathrm{g} / \mathrm{mL}$, and the intra- and interassay coefficients of variation were $2.9 \%$ and $3.5 \%$, respectively. A search for abnormal elements in the sediment and urinary culture were carried out on the 3 occasions. The presence of urinary infection required a new urine sample to be collected after the culture was negative due to antibiotic treatment guided by the antibiogram.

The casual blood pressure was obtained by calculating the mean of 3 blood pressure measures recorded with a mercury sphygmomanometer after 5 minutes with the patient seated at rest in the 3 times the patient took the urine samples to the hospital. The Korotkoff phase $\mathrm{V}$ was used as the diastolic blood pressure ${ }^{10}$. Ambulatory blood pressure monitoring was performed with the oscillometric type of SpaceLabs 90207 units, which were totally automatic and programmed to evaluate measures at an interval of 15 minutes between 6:00 and 23:00 hours and at every 20 minutes between 23:01 and 5:59 hours. The devices were installed in the morning, and the patients were instructed to perform their usual activities during monitoring and to document the time they went to sleep and woke up. The periods of sleep and wakefulness were individually determined according to the report provided at the end of the ambulatory blood pressure monitoring. The examinations had a minimum duration of 24 hours, and they were considered valid when at least $85 \%$ of the readings were valid with valid mea- surements of 2 readings per hour ${ }^{12,13}$. The mean values of systolic blood pressure, of diastolic blood pressure, and of heart rate were recorded in 24 hours, during wakefulness and sleep for each patient. The systolic pressure load was defined as the prevalence of recordings of the systolic blood pressure $>140 \mathrm{mmHg}$ during wakefulness and $>120 \mathrm{mmHg}$ during sleep. The diastolic pressure load was defined as the prevalence of recordings of diastolic blood pressure $>90 \mathrm{~mm}$ $\mathrm{Hg}$ during wakefulness and $>80 \mathrm{mmHg}$ during sleep ${ }^{12,14,15}$. The systolic and diastolic pressure drops during sleep were individually calculated ${ }^{12}$. The weight and height variables were measured, and the body mass index was calculated $\left(\mathrm{kg} / \mathrm{m}^{2}\right)$. Duration of the diabetes and the daily dose of insulin were also recorded.

The Student $t$ test was used for comparing noncategorical variables if the variables had a normal distribution (Shapiro test) and a homogeneous variance (Bartlett's test). For variables without a normal distribution, the nonparametric Mann-Whitney test was used. The chi-square test and the Fisher test were used for comparing categorical variables. The correlation between numerical variables was calculated through the Spearman correlation coefficient. For statistical calculation, the following software was used: Statistical Package for the Social Science (SPSS, version 6.0) and EPI INFO (version 6.0). The values of the variables were expressed as mean \pm standard deviation, and the duration of the diabetes and the pressure load were expressed as median and variation because they do not have a normal distribution. A $\mathrm{p}<0.05$ was considered significant.

\section{Results}

We found 9 patients who met the criteria for microalbuminuria. The duration of the diabetes did not differ substantially between the groups (table I), and the casual systolic blood pressure was greater in the microalbuminuric diabetic patients $(113.5 \pm 7.1$ vs $106.4 \pm 7.9 \mathrm{mmHg} ; \mathrm{p}=0.021)$.

The mean pressure values during ambulatory blood pressure monitoring were higher in the microalbuminuric patients, and the systolic blood pressure during sleep sho-

\begin{tabular}{|c|c|c|c|}
\hline \multicolumn{4}{|c|}{$\begin{array}{c}\text { Table I - Epidemiological and clinical data of the groups } \\
\text { stratified by the presence of microalbuminuria }\end{array}$} \\
\hline Variables & $\begin{array}{l}\text { Microalbum } \\
\text { diabetic patients } \\
\quad(n-9)\end{array}$ & $\begin{array}{l}\text { Normoalbum } \\
\text { diabetic patients } \\
\qquad(\mathrm{n}-28)\end{array}$ & $\begin{array}{l}\text { Significance } \\
\text { level }\end{array}$ \\
\hline Age & $24.8 \pm 5.4$ & $27.0 \pm 7.1$ & $\mathrm{p}=0.605$ \\
\hline $\operatorname{Sex}(M / F)$ & $4 / 5$ & $11 / 17$ & $\mathrm{p}=0.787$ \\
\hline Color $(\mathrm{W} / \mathrm{NW})$ & V) $\quad 4 / 5$ & $14 / 14$ & $\mathrm{p}=0.775$ \\
\hline BMI & $22.6 \pm 3.4$ & $22.1 \pm 2.4$ & $p=0.608$ \\
\hline Duration & $11(5-18)$ & $7(1-34)$ & $\mathrm{p}=0.078$ \\
\hline Insulin & $60.8 \pm 23.2$ & $49.8 \pm 17.8$ & $\mathrm{p}=0.140$ \\
\hline Casual SBP & $113.5 \pm 7.1$ & $106.4 \pm 7.9$ & $\mathrm{p}=0.021^{*}$ \\
\hline Casual DBP & $80.6 \pm 6.9$ & $77.8 \pm 6.5$ & $\mathrm{p}=0.260$ \\
\hline \multicolumn{4}{|c|}{$\begin{array}{l}\text { M- male; F- female; W- white; NW- nonwhite; BMI- body mass index; } \\
\text { SBP- systolic blood pressure; DBP- diastolic blood pressure. }{ }^{*} \text { p with } \\
\text { statistical significance. }\end{array}$} \\
\hline
\end{tabular}


wed the greater difference between the groups $(120.1 \pm 8.3$ vs $110.8 \pm 7.1 \mathrm{mmHg} ; \mathrm{p}=0.002)$, but the heart rate during sleep was higher in the microalbuminuric patients $(79 \pm 12$ vs $71 \pm 9$ bpm; $\mathrm{p}=0.038$; table II).

The microalbuminuric diabetic patients showed the greatest pressure loads in all periods (table III), mainly in regard to the systolic pressure load during wakefulness [6.3 (2.9-45.9) vs $1.6(0-16 \%) ; \mathrm{p}=0.001]$ and in $24 \mathrm{~h}[15.3(4.7-58.5)$ vs $4.85(0-23.5 \%) ; \mathrm{p}=0.003]$. We observed the association of systolic pressure load $>50 \%$ (4/9 vs $1 / 28 ; \mathrm{p}=0.008)$ and diastolic pressure load $>30 \%$ during sleep $(4 / 9$ vs $1 / 28 ; p=0.008$ ) with the presence of microalbuminuria. In the microalbuminuric group, we observed 3 patients with both alterations, one with an increase only in the systolic pressure load, and another with an increase only in the diastolic pressure load. In the normoalbuminuric patients, we observed one patient with a systolic pressure load $>50 \%$ and another with a diastolic pressure load $>30 \%$. The pressure drop did not differ between the micro- and normoalbuminuric diabetic patients,

\begin{tabular}{|c|c|c|c|}
\hline \multicolumn{4}{|c|}{$\begin{array}{c}\text { Table II - Pressure and heart rate means (mmHg) obtained with } \\
\text { ambulatory blood pressure monitoring in micro- and normoalbu- } \\
\text { minuric diabetic patients }\end{array}$} \\
\hline Variables & $\begin{array}{l}\text { Microalbum } \\
\text { diabetic patients } \\
\quad(n-9)\end{array}$ & $\begin{array}{l}\text { Normoalbum } \\
\text { diabetic patients } \\
\quad(n-28)\end{array}$ & $\begin{array}{c}\text { Significance } \\
\text { level }\end{array}$ \\
\hline $24 \mathrm{~h}$ SBP & $124.8 \pm 7.9$ & $116.7 \pm 6.3$ & $\mathrm{p}=0.021 *$ \\
\hline 24h DBP & $78.6 \pm 5.2$ & $73.7 \pm 5.1$ & $\mathrm{p}=0.018^{*}$ \\
\hline Waking SBP & $126.6 \pm 7.8$ & $119.0 \pm 6.6$ & $\mathrm{p}=0.007 *$ \\
\hline Waking DBP & $80.6 \pm 4.7$ & $76.3 \pm 5.5$ & $\mathrm{p}=0.042 *$ \\
\hline Sleep SBP & $120.1 \pm 8.3$ & $110.8 \pm 7.1$ & $\mathrm{p}=0.002 *$ \\
\hline Sleep DBP & $72.2 \pm 7.6$ & $66.0 \pm 6.1$ & $\mathrm{p}=0.016^{*}$ \\
\hline 24h HR & $89.8 \pm 12.5$ & $83.8 \pm 8.5$ & $\mathrm{p}=0.110$ \\
\hline Waking HR & $93.7 \pm 12.8$ & $88.0 \pm 9.2$ & $\mathrm{p}=0.154$ \\
\hline Sleep HR & $79.1 \pm 12.0$ & $70.9 \pm 9.2$ & $\mathrm{p}=0.038^{*}$ \\
\hline
\end{tabular}

\begin{tabular}{|c|c|c|c|}
\hline \multicolumn{4}{|c|}{$\begin{array}{c}\text { Table III - Pressure load during } 24 \mathrm{~h} \text {, during wakefulness and } \\
\text { during sleep }(\%) \text { in micro- and normoalbuminuric diabetic patients }\end{array}$} \\
\hline Variables & $\begin{array}{c}\text { Microalbum } \\
\text { diabetic patients } \\
(\mathrm{n}-9)\end{array}$ & $\begin{array}{c}\text { Normoalbum } \\
\text { diabetic patients } \\
(\mathrm{n}-28)\end{array}$ & $\begin{array}{l}\text { Significance } \\
\text { level }\end{array}$ \\
\hline 24h SPL & $\begin{array}{c}15.3 \\
(4.7-58.5)\end{array}$ & $\begin{array}{c}4.85 \\
(0-23.5)\end{array}$ & $\mathrm{p}=0.003^{*}$ \\
\hline 24h DPL & $\begin{array}{c}13.4 \\
(6.6-36)\end{array}$ & $\begin{array}{c}5.8 \\
(0-19.5)\end{array}$ & $\mathrm{p}=0.004^{*}$ \\
\hline Waking SPL & $\begin{array}{c}6.3 \\
(2.9-45.9)\end{array}$ & $\begin{array}{c}1.6 \\
(0-16)\end{array}$ & $\mathrm{p}=0.001^{*}$ \\
\hline Waking DPL & $\begin{array}{c}13.1 \\
(6.2-31)\end{array}$ & $\begin{array}{c}5.55 \\
(0-25.5)\end{array}$ & $\mathrm{p}=0.006^{*}$ \\
\hline Sleep SPL & $\begin{array}{c}45 \\
(0-95.2)\end{array}$ & $\begin{array}{c}11.9 \\
(0-52.4)\end{array}$ & $\mathrm{p}=0.024^{*}$ \\
\hline Sleep DPL & $\begin{array}{c}14.3 \\
(0-71.4)\end{array}$ & $\begin{array}{c}2.4 \\
(0-36.8)\end{array}$ & $\mathrm{p}=0.020 *$ \\
\hline $\begin{array}{l}\text { SPL- systolic } \\
\text { statistical sigr }\end{array}$ & $\begin{array}{l}\text { pressure load; DI } \\
\text { nificance. }\end{array}$ & - diastolic pressur & oad; * p with \\
\hline
\end{tabular}

the systolic blood pressure drop being $5.1 \pm 3.5$ vs $6.8 \pm 4.4 \%$; $\mathrm{p}=0.276$ and the diastolic blood pressure drop being $10.4 \pm 6.9$ vs $13.5 \pm 5.5 \% ; p=0.183$. The casual systolic blood pressure showed a weak correlation with the urinary excretion rate of albumin $\left(r_{s}=0.36 ; p=0.031\right)$. However, we observed a strong correlation between the pressure measurements obtained during ambulatory blood pressure monitoring and the urinary excretion of albumin, and the systolic blood pressure during sleep was the pressure variable that showed the best correlation $\left(\mathrm{r}_{\mathrm{s}}=0.55 ; \mathrm{p}<0.001\right)$. We also found a strong correlation between the pressure load and the urinary excretion of albumin. The value of systolic pressure load in $24 \mathrm{hs}\left(\mathrm{r}_{\mathrm{s}}=0.57 ; \mathrm{p}<0.001\right)$ and mainly during wakefulness $\left(\mathrm{r}_{\mathrm{s}}=0.61, \mathrm{p}<0.001\right)$ were the variables of the ambulatory blood pressure monitoring that had the strongest correlation with the urinary excretion of albumin. We found no correlation between the systolic and diastolic pressure drops and the urinary excretion of albumin. Age was another variable that showed no correlation with the variables of the ambulatory blood pressure monitoring.

\section{Discussion}

Insulin-dependent diabetic patients with microalbuminuria have been reported to have a casual blood pressure higher than that of normoalbuminuric patients ${ }^{16-18}$, and this is in accordance with our findings.

The main issue when analyzing the association between the elevation in blood pressure and microalbuminuria in the insulin-dependent diabetic patient is to know whether these alterations occur simultaneously and also whether the increase in blood pressure is primary or secondary to microalbuminuria. The Microalbuminuria Collaborative Study Group ${ }^{18}$ comprising 137 normoalbuminuric insulin-dependent diabetic patients followed up for 4 years showed a higher level of glycosylated hemoglobin, of urinary excretion rate of albumin, and of casual blood pressure at the beginning of the study of patients who evolved to persistent microalbuminuria. The multiple regression analysis showed a correlation in the urinary excretion rate of albumin, the casual blood pressure, and tobacco use with the appearance of microalbuminuria, suggesting a concomitant elevation in urinary excretion of albumin and in the casual blood pressure before the appearance of microalbuminuria.

In 1982, Rubler et al ${ }^{19}$ performed for the first time ambulatory blood pressure monitoring in diabetic patients and observed higher pressure levels at night, and they associated these alterations with the presence of autonomic neuropathy. The first works of ambulatory blood pressure monitoring in normotensive insulin-dependent diabetic patients relating the mean pressure values to the urinary excretion rate of albumin were performed at the beginning of the $90 \mathrm{~s}^{7-9}$. Ambulatory blood pressure monitoring is more accurate for detecting higher pressure levels in microalbuminuric insulindependent diabetic patients compared with normoalbuminuric patients than the casual measure of blood pressure ${ }^{7}$.

In a study ${ }^{9}$ comprising 38 insulin-dependent diabetic 
patients during ambulatory blood pressure monitoring, a higher blood pressure in 24 hours and at night was obtained in the microalbuminuric patients. In another study ${ }^{8}$ comprising 68 insulin-dependent diabetic patients during ambulatory blood pressure monitoring, higher systolic and diastolic blood pressure were also obtained in microalbuminuric patients during the 24-hour, daily and nocturnal periods. Our study showed in microalbuminuric insulin-dependent diabetic patients a higher mean pressure level in 24 hours, at wakefulness and during sleep as compared with normoalbuminuric patients, being, therefore, in accordance with the literature ${ }^{7-9}$.

It is agreed that normotensive microalbuminuric insulin-dependent diabetic patients have higher pressure levels during sleep as compared with normoalbuminuric patients during ambulatory blood pressure monitoring, mainly in regard to systolic blood pressure. Some studies have also shown this relation for the period of 24 hours, but the results are controversial when the blood pressure at wakefulness is analyzed. This controversy in findings may be due to the difficulty in characterizing whether the periods of sleep and wakefulness adopted in a fixed way actually corresponded to those of the patients. Another cause of controversy may be the differences in the protocol used for defining the periods of sleep and wakefulness and also the number of measurements in each period ${ }^{20}$. Other factors related to the population studied, such as age, duration of illness, degree of glomerular involvement, and degree of autonomic impairment should play an important role.

The pressure load obtained with ambulatory blood pressure monitoring has a strong relation with the involvement of the target organ by arterial hypertension, and a positive correlation is described between the pressure load and the left ventricular mass ${ }^{15}$. The occurrence of a greater pressure load in normotensive insulin-dependent diabetic patients was first reported in $1990^{21}$. The association of an increased pressure load with microalbuminuria in the insulindependent diabetic patient was initially reported in $1992^{8,9}$. Hansen et al ${ }^{8}$ found a higher pressure load during wakefulness in microalbuminuric insulin-dependent diabetic patients as compared with that of normoalbuminuric patients. In another study ${ }^{9}$, a higher pressure load in 24 hours, during wakefulness and during sleep was observed in microalbuminuric insulin-dependent diabetic patients.

In our study, we observed a higher pressure load in 24 hours, during wakefulness and during sleep when comparing microalbuminuric diabetic patients with normoalbuminuric diabetic patients. In addition, we found a correlation between pressure load and urinary excretion of albumin. These findings suggest that the presence of microalbuminuria is strongly related to the increase in pressure load. The association of a systolic pressure load $>50 \%$ and a diastolic pressure load $>30 \%$ during sleep with microalbuminuria is an interesting finding and deserves further study with a larger case series to define its predictive value in regard to nephropathy.

The association of autonomic neuropathy and diabetic nephropathy is highly prevalent ${ }^{22,23}$. Even though we have found in absolute figures a lower drop in the systolic and diastolic blood pressures in microalbuminuric diabetic patients as compared with that in normoalbuminuric diabetic patients, unlike other authors ${ }^{9,24}$, we have found no significant difference, which could be attributed to the clinical characteristics of the diabetic group studied and also to the small size of the sample, which could induce statistical errors of the beta type (2).

Other authors, however, have found results similar to those of our study. During the evaluation of 33 insulin-dependent diabetic patients, a greater mean pressure level was observed in the microalbuminuric subgroup; the sleep/ wakefulness variation in blood pressure, however, did not differ among the subgroups ${ }^{25}$. In the same way, Cesarini et al ${ }^{26}$ observed a lower drop in mean blood pressure at night in insulin-dependent diabetic patients, but they did not differentiate the pressure circadian rhythm of the diabetic patients in regard to the presence of microalbuminuria.

The presence of a higher heart rate during sleep in microalbuminuric diabetic patients emphasized in our study has already been observed and related to a concomitant dysautonomia ${ }^{7,24}$. Assessing the autonomic function, however, would require more sensitive methods such as the spectral analysis of power by Holter monitoring.

Diabetic nephropathy is an important cause of chronic renal failure. Therefore, early diagnostic methods for detecting renal involvement in diabetes mellitus are extremely valuable for this population. Determining microalbuminuria represents a great development in this regard, and ambulatory blood pressure monitoring is another tool for assessing insulin-dependent diabetic patients, because it shows higher pressure means and loads in microalbuminuric diabetic patients.

Our study has some limitations because it is a crosssectional study assessing a small number of patients. We believe a prospective study is necessary to better define the value of the alterations found during ambulatory blood pressure monitoring in the progression of cardiovascular and renal complications in microalbuminuric insulin-dependent diabetic patients.

\section{Acknowledgements}

We would like to thank Dr. Roberto Pozzan and Mrs. Eliete Leão for their support. 


\section{References}

1. Borch-Johnsen K, Kreiner S. Proteinuria: value as a predictor of cardiovascular mortality in insulin-dependent diabetes mellitus. Br Med J 1987; 294: 1651-4.

2. Epstein M, Sowers J. Diabetes mellitus and hypertension. Hypertension 1992; 19: 403-18

3. Mogensen CE, Christensen CK. Predicting diabetic nephropathy in insulindependent patients. N Engl J Med 1984; 311: 89-93.

4. Diabetic Nephropathy. American Diabetes Association. Diabetes Care 1997; 20 (Suppl 1): S24 - S27.

5. Deckert T, Kofoed-Enevoldsen A, Norgaard K, Borch-Johnsen K, Feldt-Rasmussen B, Jensen T. Microalbuminuria: Implications for micro and macrovascular disease. Diabetes Care 1992; 15: 1181-91.

6. Mogensen CE. Microalbuminuria predicts clinical proteinuria and early mortality in maturity-onset diabetes. N Engl J Med 1984; 310: 356.

7. Benhamou PY, Halimi S, Gaudemaris R, et al. Early disturbances of ambulatory blood pressure load in normotensive type I diabetic patients with microalbuminuria. Diabetes Care 1992; 15: 1614-9.

8. Hansen KW, Christensen CK, Andersen PH, Pedersen MM, Christiansen JS, Mogensen CE. Ambulatory blood pressure in microalbuminuric type I diabetic patients. Kidney Int 1992; 41: 847-54.

9. Moore WV, Donaldson DL, Chonko AM, Ideus P, Wiegmann TB. Ambulatory blood pressure in type I diabetes mellitus: comparison to presence of incipient nephropathy in adolescents and young adults. Diabetes 1992; 41: 1035-41.

10. Fifth Report of The Joint National Committee on Detection, Evaluation, and Treatment of High Blood Pressure (JNC V). Arch Intern Med 1993; 153: 154-83.

11. Mckenna MJ, Arias C, Feldkamp CS, Whitehouse FW. Micro albuminuria in clinical practice. Arch Intern Med 1991; 151: 1745-7.

12. II Consenso Brasileiro para o uso da Monitorização Ambulatorial da Pressão Arterial. Arq Bras Cardiol 1997; 69: 359-67.

13. National High Blood Pressure Education Program Work Group Report on Ambulatory Blood Pressure Monitoring. The National High Blood Pressure Education Program Coordinating Committee. Arch Intern Med 1990; 150: 2270-80.

14. Staessen JA, Fagard RH, Lijnen PJ, Thijs L, Hoof RV, Amery AK. Mean and range of the ambulatory pressure in normotensive subjects from a meta-analysis of 23 studies. Am J Cardiol 1991; 67: 723-7.

15. White WB, Dey HM, Schulman P. Assessment of the daily blood pressure load as a determinant of cardiac function in patients with mild-to-moderate hypertension. Am Heart J 1989; 118: 782-95.

16. Gomes MB, Lucchetti MR, Gazzola H, Dimetz T, Lobão VI, stum JA. Perfil lipídico, microalbuminúria e pressão arterial sistêmica em pacientes com diabetes insulino-dependente. Arq Bras Cardiol 1997; 68: 85-9.

17. Mathiesen ER, Oxenboll B, Johansen K, Svendensen PA, Deckert T. Incipient nephropathy in type I (insulin-dependent) diabetes. Diabetologia 1984; 26: 406-10.

18. Microalbuminuria Collaborative Study Group. Risk factors for development of microalbuminuria in insulin dependent diabetic patients: a cohort study. Br Med J 1993; 306: 1235-9.

19. Rubler S, Abenavoli T, Greenblatt HA, Dixon JF, Cieslik CJ. Ambulatory blood pressure monitoring in diabetic males: a method for detecting blood pressure elevations undisclosed by conventional methods. Clin Cardiol 1982; 5: 447-54.

20. Hansen KW, Poulsen PL, Mogensen CE. Ambulatory blood pressure and abnormal albuminuria in type I diabetic patients. Kidney Int 1994; 45(suppl 45): S134-S-49.

21. Wiegmann TB, Herron KG, Chonko AM, Macdougall ML, Moore WV. Recognition of hypertension and abnormal blood pressure burden with ambulatory blood pressure recordings in type I diabetes mellitus. Diabetes 1990; 39: 1556-60.

22. Molgaard H, Christensen PD, Sorensen KE, Christensen CK, Mogensen CE. Association of 24-h cardiac parasympathetic activity and degree of nephropathy in IDDM patients. Diabetes 1992; 41: 812-7.

23. Spallone V, Gambardella S, Maiello MR, Barini A, Frontoni S, Menzinger G. Relationship between autonomic neuropathy, 24-h blood pressure profile, and nephropathy in normotensive IDDM patients. Diabetes Care 1994; 17: 578-84.

24. Lurbe A, Redón J, Pascual JM, Tacons J, Alvarez V, Batlle DC. Altered blood pressure during sleep in normotensive subjects with type I diabetes. Hypertension 1993; 21: 227-35.

25. Spallone V, Gambardella S, Maiello MR, Frontoni S, Menzinger, G. Altered 24h blood pressure profile in type 1 diabetes is associated with autonomic neuropathy and not with microalbuminuria. Diabetologia 1993; 36(suppl 1): A 26.

26. Cesarini PR, Ferreira SRG, Monteagudo PT,Zanella MT. Monitorização da pressão arterial de 24 horas: método para diagnóstico precoce da complicação renal no diabetes mellitus insulino-dependente? Arq Bras Endocrinol Metab 1996; 40: 172-9. 